Óleos Essenciais dos Frutos e Folhas de Kielmeyera coriacea: Atividade Antitumoral e Estudo Químico

\author{
Lemes, R. S.; Costa, G. C. S.; Silva, D. C. S.; Becceneri, A. B.; Bicalho, K. U.; \\ Miranda, M. L. D.; Diniz, V. S. S.; Cazal, C. M.*
}

Rev. Virtual Quim., 2017, 9 (3), 1245-1257. Data de publicação na Web: 17 de abril de 2017

http://rvq.sbq.org.br

\title{
Essential Oils from Fruits and Leaves of Kielmeyera coriacea: Antitumor Activity and Chemical Study
}

Abstract: Kielmeyera coriacea, a typical tree species of the Cerrado (Brazilian Savanna), popularly known as "pausanto" and it is used in traditional medicine for the treatment of various diseases. This study aimed to chemically characterize the essential oils of leaves and fruits of $K$. coriacea and to evaluate its antitumor activity against human tumor cell lines MDA-MB-231 (breast tumor) and DU-145 (prostate tumor) as a way to search for new drugs derived from natural sources. Essential oils were extracted by hydrodistillation in Clevenger. The average yield of essential oil of leaves and fruits was $0.38 \%$ and $0.0041 \%$, respectively. In leaves from $K$. coriacea, the major compounds found in the essential oils, were geranyl linalool $(27,78)$, 2- Acetate (2E) Tridecenol (9.06\%), E-nerolidol (7.70\%) and $\alpha$-bisabolol $(5,09)$. The major compounds found in essential oils of fruits were D-germacrene $(18.94 \%)$, neointermedeol (12.18\%), bicyclogermacrene (12.00\%), Viridiflorol (9,30\%), Globulol (8,76\%), Epi- $\alpha$-muurolol $(8,13 \%)$ and $\delta$-cadinene $(5,00 \%)$.. The essential oils of fruits inhibited the proliferation of tumor cell lines DU-145 and MDAMB-231, as well as of the non-tumor cells (FH -Human fibroblasts). By contrast the essential oils of leaves were not active in any tested tumor lineage. To our knowledge, this is the first report on the chemical composition and antitumor activity of this species, and it clearly enhance our chemical knowledge of this plant.

Keywords: Brazilian cerrado; cancer; chemical composition; natural products; pau-santo.

\section{Resumo}

Kielmeyera coriacea é uma planta típica do Cerrado, conhecida como pau-santo, sendo muito utilizada pela medicina popular no tratamento de diversas doenças. O presente trabalho teve como objetivo caracterizar quimicamente os óleos essenciais dos frutos e das folhas de $K$. coriacea e avaliar sua atividade antitumoral frente às linhagens de células tumorais humanas MDA-MB-231(tumor mama) e DU-145 (tumor de próstata) na busca de novos compostos bioativos de origem natural. Os óleos essenciais foram extraídos por hidrodestilação em aparato Clevenger. O rendimento dos óleos essenciais das folhas e frutos foi de 0,38 \% e 0,0041 \%, respectivamente. Os compostos majoritários presentes no óleo essencial das folhas de $K$. coriacea, foram: geranil linalool (27,78\%), 2Acetato de $(2 E)$-tridecenol $(9,06 \%)$, E-nerolidol $(7,70 \%)$ e $\alpha$-bisabolol. Já no óleo essencial dos frutos os constituintes majoritários identificados foram: D-germacreno $(18,94 \%)$, neo-intermedeol $(12,18 \%)$, biciclogermacreno (12,00\%), Viridiflorol (9,30\%), Globulol (8,76\%), Epi- $\alpha$-muurolol $(8,13 \%)$ e $\delta$-cadineno $(5,00 \%)$. 0 óleo essencial dos frutos inibiu a ploriferação celular das linhagens tumorais DU-145 e MDA-MB-231 e das celulas não tumorais (FH-fibroblastos humano), enquanto que o óleo essencial das folhas não exibiu atividade frente a nenhuma linhagem tumoral testada. Este é o primeiro relato da composição química do óleo essencial dos frutos de Kielmeyera coriacea, contribuindo para o conhecimento desta espécie.

Palavras-chave: Cerrado brasileiro; câncer; composição química; produtos naturais; pau-santo.

* Instituto Federal de Educação, Ciência e Tecnologia do Sudeste de Minas Gerais, Campus Barbacena, CEP 36205018, Barbacena-MG, Brasil.

$M$ cristiane.cazal@ifsudestemg.edu.br

DOI: $10.21577 / 1984-6835.20170073$

Rev. Virtual Quim. |Vol 9| |No. 3| |1245-1257| 


\title{
Óleos Essenciais dos Frutos e Folhas de Kielmeyera coriacea: Atividade Antitumoral e Estudo Químico
}

\author{
Raiane S. Lemes, ${ }^{a}$ Géssica Carla S. Costa, ${ }^{a}$ Douglas Carlos S. Silva, ${ }^{a}$ \\ Amanda B. Becceneri, ${ }^{b}$ Keylla U. Bicalho, ${ }^{b}$ Mayker Lazaro D. Miranda, ${ }^{c}$ \\ Vania S. S. Diniz, ${ }^{a}$ Cristiane M. Cazal ${ }^{\mathrm{d}, *}$ \\ ${ }^{a}$ Instituto Federal de Educação, Ciência e Tecnologia Goiano, CEP 76200-000, Iporá-GO, Brasil. \\ ${ }^{b}$ Universidade Federal de São Carlos, CEP 13565-905, São Carlos-SP, Brasil. \\ 'Instituto Federal de Educação, Ciência e Tecnologia do Sul de Minas Gerais, CEP 37550-000, \\ Pouso Alegre-MG, Brasil. \\ d Instituto Federal do Sudeste de Minas Gerais, CEP 36205-018, Barbacena-MG, Brasil. \\ * cristiane.cazal@ifsudestemg.edu.br
}

Recebido em 16 de janeiro de 2017. Aceito para publicação em 4 de abril de 2017

\section{Introdução}

\section{Parte Experimental}

2.1. Material vegetal

2.2. Extração dos óleos essenciais

2.3. Análise dos óleos essenciais

2.4. Cultura de células

2.5. Experimento de proliferação celular

\section{Resultados e Discussão}

\section{Conclusão}

\section{Introdução}

O Cerrado é o segundo maior bioma brasileiro e possui uma considerável diversidade biológica em sua flora. Sua grande extensão e posição geográfica compreendem uma ampla diversidade de litologias, formas de relevo, cotas altimétricas e solos. Desta maneira, o Cerrado brasileiro é considerado uma fonte de recursos biológicos possuindo um grande número de espécies frutíferas, ornamentais e medicinais. ${ }^{1}$

Segundo Martins e colaboradores, devido a essa grande diversidade, houve um aumento do interesse pelas plantas medicinais neste bioma, em busca de espécies com amplo espectro farmacológico para o tratamento de diferentes patologias. ${ }^{2}$

A família Calophyllaceae possui 13 gêneros com aproximadamente 460 espécies, sendo importante do ponto de vista 
etnobotânico e econômico. . Dentro desta família está o gênero Kielmeyera, endêmico da América do Sul, que possui 47 espécies, das quais 45 são originárias do Brasil, sendo encontradas em diversos habitats. ${ }^{4}$ Espécies deste gênero vêm sendo utilizadas pela medicina popular para o tratamento de doenças tropicais como malária, esquistossomose, infecção por bactérias e fungos, leishmaniose entre outras. ${ }^{5}$

Uma espécie que merece destaque dentro desse gênero é a Kielmeyera coriacea, uma planta arbórea, tipicamente do Cerrado, e é conhecida popularmente como pausanto. ${ }^{6}$ Seus extratos e óleos essenciais são extensivamente estudados e se destacam por apresentarem propriedades fungicidas $\mathrm{e}$ atuarem como uma possível fonte de compostos antidepressivo, anti-ulcerosos, anti-ansiedade e anti-tumor. ${ }^{4}$

Existem alguns estudos relacionados à identificação de compostos químicos desta espécie e sua atividade anticancerígena. ${ }^{7-14}$ É reportado na literatura $\mathrm{o}$ isolamento $\mathrm{e}$ identificação de substâncias derivadas do floroglucinol poliprenilados em extratos hexânicos de K.coriacea e K. lathrophyton, ${ }^{13}$ sendo descrito que os acil floroglucinóis poliprenilados isolados destas plantas possuem atividade anticancerígena in vivo e in vitro. ${ }^{14}$

O estudo químico e biológico de óleos essenciais obtidos de diversas espécies vegetais tem recebido destaque, principalmente quando envolvem atividade antitumoral. ${ }^{15,16}$ Entretanto, até o momento não há relato da avaliação dos óleos essenciais de $K$. coriacea frente a proliferação celular.

Neste contexto, o presente trabalho teve como objetivo realizar o estudo químico dos óleos essenciais das folhas e frutos de $K$. coriacea, contribuindo para o conhecimento da espécie, bem como avaliar sua atividade antiproliferativa frente às linhagens de células tumorais humanas MDA-MB-231 (tumor mama), DU-145 (tumor de próstata) e a linhagem não tumoral FH (fibroblastos).

\section{Parte Experimental}

\subsection{Materiais vegetais}

As folhas e os frutos de $K$. coriacea foram coletados na região de Iporá-GO em agosto de 2012. O material vegetal foi identificado e uma amostra foi depositada no Herbário Jataiense Professor Germano Guarin Neto sob o registro no HJ 3807.

\subsection{Extração dos óleos essenciais}

As folhas e os frutos frescos (500g) foram reduzidos em moinho de facas e submetidos às extrações dos óleos essenciais pelo método de hidrodestilação em aparelho do tipo Clevenger, por um período de 4 horas a partir da ebulição. ${ }^{17} \mathrm{Em}$ seguida, o hidrolato foi submetido à três partição líquido-líquido utilizando $10 \mathrm{~mL}$ de diclorometano em cada. Os óleos essenciais extraídos foram secos com sulfato de sódio anidro, acondicionados em pequenos frascos de vidro âmbar e mantidos sob refrigeração $\left(4{ }^{\circ} \mathrm{C}\right)$ até a realização da atividade antitumoral e análise por CG-EM (Cromatografia Gasosa acoplada a Espectrometria de Massa).

\subsection{Análise dos óleos essenciais por CG-} EM

A composição química dos óleos essenciais foi determinada em cromatógrafo gasoso Shimadzu GC QP 5000 acoplado ao espectrômetro de massas (Shimadzu, Kyoto, Japan), equipado com uma coluna capilar de sílica fundida OPTIMA ${ }^{\circledR}-5-0,25 \mu \mathrm{m}$ (30 m x $0,25 \mathrm{~mm}$ ) e ionização por impacto eletrônico (IE) $(70 \mathrm{eV})$. A temperatura inicial foi mantida a 80 ㅇ $\mathrm{C}$ por $3 \mathrm{~min}$, em seguida programada até $200 \stackrel{\circ}{\circ}$ a 4 o $C / m i n$ e permaneceu nessa temperatura por mais 3,0 min e finalmente foi programada até $280 \stackrel{\circ}{\circ}$ a $20 \stackrel{\circ}{\circ} / \mathrm{min}$ e mantida por 1,0 min. A temperatura do 
injetor foi de $260{ }^{\circ} \mathrm{C}$ e do detector $280{ }^{\circ} \mathrm{C}$. A pressão de injeção foi $100 \mathrm{KPa}$. $O$ gás de arraste utilizado foi hélio, usado à pressão constante de 100 Kpa e vazão constante de $1,6 \mathrm{~mL} / \mathrm{min}$. O espectrômetro operou com velocidade de 0,5 scans $/ \mathrm{seg}$. O tempo necessário para analise dos óleos essenciais foram 36,5 e 20,0 min para os frutos e folhas, respectivamente. A porcentagem de cada componente foi obtida do próprio CG-EM (GCMS Solutions) e foi determinada dividindo-se a área de cada pico pela área total de todos os componentes presentes na mistura. A identificação dos componentes dos óleos essenciais foi baseada no índice de retenção (Equação 1) calculado em relação aos tempos de retenção de uma série homóloga de $n$-alcanos (C-14 a C-26, C-28 e C-30), no padrão de fragmentação observado nos espectros de massas e por comparação destes com dados da literatura ${ }^{18}$ e da espectroteca Nist 98.

$$
I R=100 i \times \frac{\mathrm{T} r_{\chi}-\mathrm{T} r_{H A}}{\mathrm{~T} r_{H P}-\mathrm{T} r_{H A}}+100 N
$$

$\operatorname{Tr}_{x}=$ Tempo de retenção do composto problema

$\operatorname{Tr}_{\text {HA }}=$ Tempo de retenção do Hidrocarboneto anterior

$\operatorname{Tr}_{\mathrm{HP}}=$ Tempo de retenção do hidrocarboneto posterior

$\mathrm{N}=$ Número de carbonos do hidrocarboneto posterior

$I$ = Diferença entre o número de carbono dos hidrocarbonetos anterior e posterior

\subsection{Cultura de células}

Para os ensaios de proliferação celular foram utilizadas três linhagens celulares humanas: MDA-MB-231 (tumor mama), DU145 (tumor de próstata) e FH (fibroblastos). As manipulações das culturas celulares foram realizadas em câmara de fluxo laminar vertifical.

As células foram cultivadas em incubadora a $37^{\circ} \mathrm{C}$ e $5 \%$ de $\mathrm{CO}_{2}$ em meio de cultura Dulbecco's Modified Eagle Medium (DMEM) contendo $10 \%$ de soro fetal bovino (SFB) e mantidas em crescimento exponencial tendose para tal subcultura por tripsinização. Para tal processo, o meio de cultura foi removido, as células foram lavadas com $5 \mathrm{~mL}$ de PBS e em seguida adicionados $2 \mathrm{~mL}$ de tripsina e incubadas em estufa a $37^{\circ} \mathrm{C}$ e $5 \%$ de $\mathrm{CO}_{2}$ por 5 minutos. A suspensão celular obtida foi centrifugada a $1000 \mathrm{rpm}$ durante 5 minutos em temperatura ambiente. $O$ sobrenadante foi descartado e as células sedimentadas foram então ressuspendidas em $5 \mathrm{~mL}$ de meio de cultura. A viabilidade celular foi avaliada utilizando o corante de exclusão, azul de tripano. Para tal, foram adicionados $10 \mu l$ de suspensão celular a $10 \mu l$ de azul de tripano e procedida a contagem em câmara de Neubauer.

\subsection{Experimento de proliferação celular}

Os efeitos dos óleos essenciais dos frutos (OEPS 1 ) e das folhas (OEPS 2 ) de $K$. coriacea sobre a proliferação das células da linhagem MDA-MB-231, DU-145 e FH foram determinados através do uso do reagente MTT [brometo de 3-(4,5-dimetil-tiazol-2-il)2,5-difeniltetrazolio] conforme descrito por Mosmann (1983). ${ }^{19}$ Para tal, as células, na concentração de $1 \times 10^{4} / 200 \mu \mathrm{L}$, foram plaqueadas em placas de 96 poços estéreis (Corning) em meio apropriado adicionado de $10 \%$ de SFB e dos suplementos adicionais. As células foram incubadas por $24 \mathrm{~h}$ a $37^{\circ} \mathrm{C}$ e $5 \%$ de $\mathrm{CO}_{2}$, após este período o meio de cultura foi retirado dos poços e diferentes concentrações $(12,5 ; 25 ; 50$ e $100 \mu \mathrm{g} / \mathrm{mL})$ dos 
óleos essenciais foram adicionadas. Como controle positivo utilizou-se o quimioterápico, doxorrubicina $(1,35 \mu \mathrm{g} / \mathrm{mL})$. Em seguida, as células foram incubadas por 48h nas mesmas condições descritas acima.

Após o tempo de incubação, o meio de cultura de cada poço foi retirado e uma solução contendo $M T T(0,5 \mathrm{mg} / \mathrm{mL})$ foi adicionada (100 $\mu \mathrm{L} /$ poço). As placas foram então mantidas durante $4 \mathrm{~h}$ a $37{ }^{\circ} \mathrm{C}$ e em seguida, os cristais formados foram diluídos em dimetilsulfóxido (DMSO) $(100 \mu \mathrm{L})$. A leitura da absorbância foi realizada em leitor de placa de ELISA, Labtech LT- 4000 Microplate Reader, em comprimento de onda de $540 \mathrm{~nm}$. Os óleos foram diluídos em DMSO a $0,5 \%$.

A medida da proliferação celular foi realizada em comparação aos poços sem tratamento apenas com meio de cultura suplementado com SFB (controle negativo). A análise estatística foi realizada utilizando o software GraphPad Prism ${ }^{\circledR}$ através da análise de variância one-way (ANOVA) seguido pelo teste de comparação múltipla de Dunnet.

\section{Resultados e Discussão}

A hidrodestilação dos frutos e das folhas da $K$. coriacea forneceu um óleo amarelado claro e com rendimento médio de 0,0041 \% e $0,38 \%$, respectivamente. A Figura 1 apresenta os cromatogramas obtidos nas condições estabelecidas para análise dos óleos essenciais dos frutos (OEPS 1 ) e folhas (OEPS 2) de K. coriacea.

No óleo essencial dos frutos de $K$. coriacea foram detectados 29 constituintes químicos (Tabela 1), enquanto que nas folhas foram detectados 28 constituintes químicos (Tabela 2).
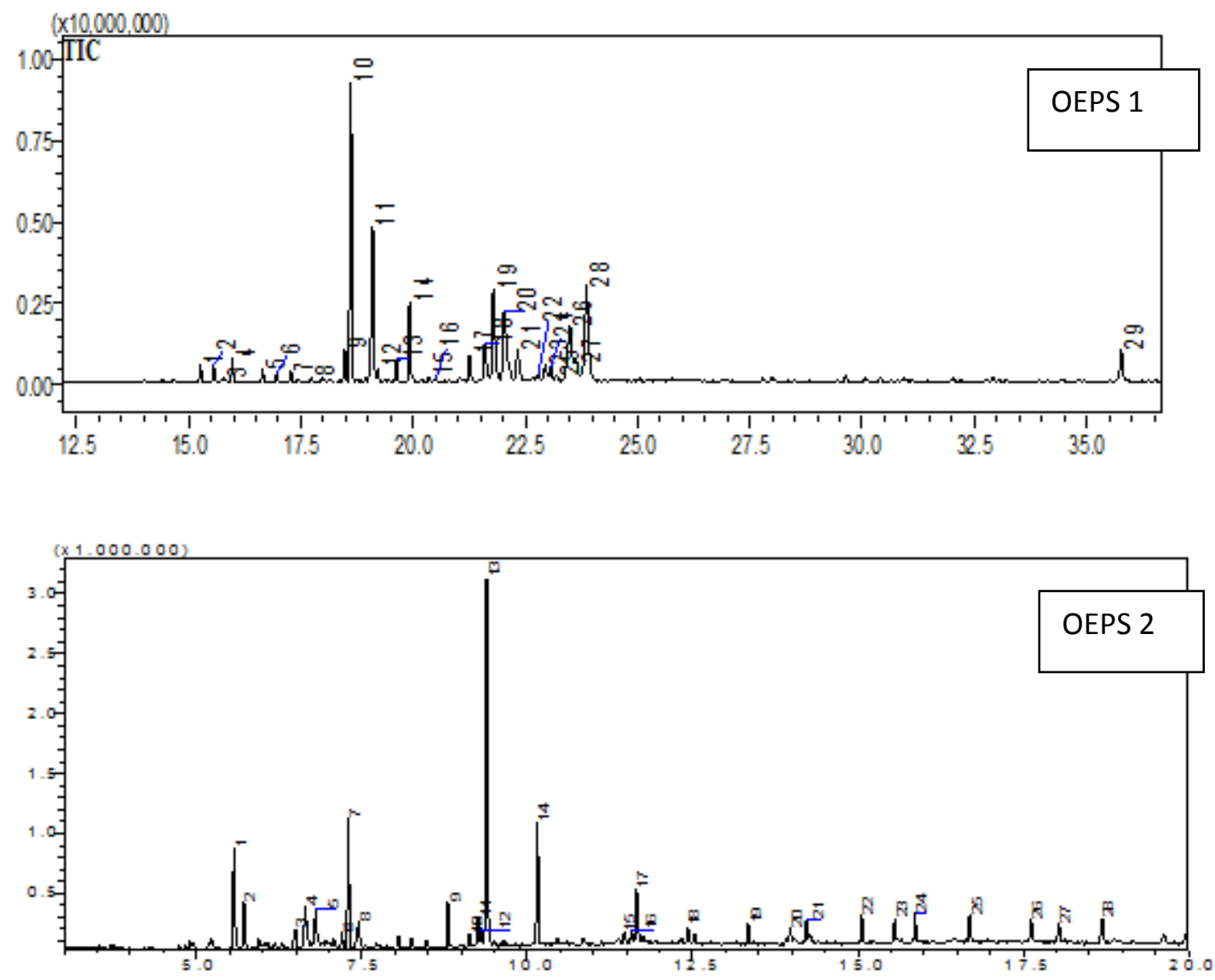

Figura 1. Cromatogramas (CG-EM) dos óleos essenciais dos frutos (OEPS 1) e das folhas (OEPS 2) de $K$. coriacea 
Tabela 1. Composição química do óleo essencial dos frutos de $K$. coriacea

\begin{tabular}{|c|c|c|c|c|c|}
\hline Pico & TR (min) & Compostos & $(\%)$ & $I^{*}$ & $\mathbf{I R}^{* *}$ \\
\hline \multicolumn{6}{|c|}{$\begin{array}{l}\text { Sesquiterpenos } \\
\text { hidrocarbonados }\end{array}$} \\
\hline 1 & 15.266 & $\alpha$-ylangeno & 0,96 & 1378 & 1373 \\
\hline 2 & 15.554 & B-bourboneno & 0,95 & 1387 & 1387 \\
\hline 3 & 15.785 & B-elemeno & 0,20 & 1394 & 1389 \\
\hline 4 & 15.974 & n-tetradecano & 1,34 & 1400 & 1400 \\
\hline 5 & 16.652 & E-cariofileno & 0,73 & 1421 & 1417 \\
\hline 6 & 16.965 & 8-copaeno & 0,45 & 1431 & 1430 \\
\hline 7 & 17.276 & Aromadendreno & 0,61 & 1441 & 1439 \\
\hline 8 & 17.737 & $\alpha$-humeleno & 0,23 & 1456 & 1452 \\
\hline 9 & 18.473 & $\mathrm{NI}$ & 1,95 & 1479 & - \\
\hline 10 & 18.612 & D-germacreno & 18,94 & 1483 & 1484 \\
\hline 11 & 19.101 & Biciclogermacreno & 12,00 & 1499 & 1500 \\
\hline 12 & 19.212 & $\alpha$-muuroleno & 0,76 & 1503 & 1500 \\
\hline 13 & 19.627 & $\gamma$-cadineno & 1,28 & 1516 & 1513 \\
\hline 14 & 19.920 & $\delta$-cadineno & 5,00 & 1526 & 1522 \\
\hline 15 & 20.349 & $\alpha$-cadineno & 0,23 & 1540 & 1537 \\
\hline 16 & 20.517 & a-calacoreno & 0,27 & 1546 & 1544 \\
\hline \multicolumn{6}{|c|}{$\begin{array}{c}\text { Sesquiterpenos } \\
\text { oxigenados }\end{array}$} \\
\hline 17 & 21.255 & Maaliol & 1,86 & 1570 & 1566 \\
\hline 18 & 21.592 & Espatulenol & 3,65 & 1581 & 1577 \\
\hline 19 & 21.787 & Globulol & 8,76 & 1590 & 1590 \\
\hline 20 & 22.022 & Viridiflorol & 9,30 & 1596 & 1592 \\
\hline 21 & 22.327 & 5-epi-7-epi- $\alpha$-eudesmol & 2,93 & 1606 & 1607 \\
\hline 22 & 22.783 & Junenol & 0,37 & 1622 & 1618 \\
\hline 23 & 22.935 & Eremoligenol & 1,28 & 1627 & 1629 \\
\hline 24 & 23.060 & 1-epi-cubenol & 0,89 & 1631 & 1627 \\
\hline 25 & 23.192 & $\mathrm{NI}$ & 0,28 & 1636 & - \\
\hline 26 & 23.487 & Epi- $\alpha$-muurolol & 8,13 & 1646 & 1640 \\
\hline 27 & 23.642 & $\alpha$-cadinol & 2,21 & 1651 & 1652 \\
\hline 28 & 23.858 & Neo-intermedeol & 12,18 & 1659 & 1658 \\
\hline 29 & 35.773 & $\mathrm{NI}$ & 2,26 & 2103 & - \\
\hline TOTAL & & & 95,51 & & \\
\hline
\end{tabular}

* = índice de retenção calculado usando a equação de Van den Dool e Kratz.

** = Índice de retenção da literatura ${ }^{18}$ baseada na equação de Van den Dool e Kratz.

$\mathrm{NI}=\mathrm{Não}$ identificado 
Lemes, R. S. et al.

Tabela 2. Composição química do óleo essencial das folhas de $K$. coriacea

\begin{tabular}{|c|c|c|c|c|c|}
\hline Pico & TR (min) & Compostos & $(\%)$ & $I^{*}$ & $\mathrm{IR}^{* *}$ \\
\hline \multicolumn{6}{|c|}{$\begin{array}{c}\text { Sesquiterpenos } \\
\text { oxigenados }\end{array}$} \\
\hline 1 & 5,565 & E-Nerolidol & 7,70 & 1572 & 1561 \\
\hline 2 & 5,713 & $\begin{array}{c}\text { (3Z)-benzoato de metil } \\
\text { Hexenil }\end{array}$ & 4,15 & 1585 & 1565 \\
\hline 3 & 6,489 & Cis-Cadin-4-en-7-ol & 2,18 & 1650 & 1635 \\
\hline 4 & 6,647 & $\alpha$-bisobolol & 5,09 & 1664 & 1656 \\
\hline 5 & 6,800 & Acetato elemol & 3,33 & 1676 & 1680 \\
\hline 6 & 7,198 & $\mathrm{NI}$ & 1,24 & 1710 & \\
\hline 7 & 7,292 & Acetato de (2E)Tridecenol & 9,06 & 1718 & 1703 \\
\hline 8 & 7,444 & $(2 Z, 6 E)$-Farnesol & 2,74 & 1731 & 1722 \\
\hline 9 & 8,803 & $\mathrm{NI}$ & 3,05 & 1849 & \\
\hline 10 & 9,129 & $\mathrm{NI}$ & 0,77 & 1878 & \\
\hline 11 & 9,256 & Salicilato de benzila & 2,20 & 1889 & 1864 \\
\hline 12 & 9,312 & n-hexadecanol & 1,08 & 1894 & 1874 \\
\hline 13 & 9,386 & Geranil linalool & 27,78 & 2000 & 1998 \\
\hline 14 & 10,154 & $\mathrm{NI}$ & 8,28 & 2072 & - \\
\hline 15 & 11,458 & $n$-heneicosano & 1,26 & 2100 & 2100 \\
\hline 16 & 11,583 & Octadenol etil & 0,76 & 2113 & 2209 \\
\hline 17 & 11,652 & $\begin{array}{c}\text { 3,7,11,15-tetrametil-2- } \\
\text { Hexadecen-1-ol }\end{array}$ & 4,18 & 2121 & 2045 \\
\hline 18 & 12,428 & $\mathrm{NI}$ & 1,05 & 2201 & \\
\hline 19 & 13,345 & $n$-tricosano & 1,37 & 2301 & 2300 \\
\hline 20 & 13,976 & $\mathrm{NI}$ & 0,43 & 2373 & - \\
\hline \multicolumn{6}{|c|}{ Alcanos } \\
\hline 21 & 14,220 & $n$-tetracosano & 1,09 & 2401 & 2400 \\
\hline 22 & 15,059 & $n$-pentacosano & 1,67 & 2502 & 2500 \\
\hline 23 & 15,550 & $\mathrm{NI}$ & 1,23 & 2563 & \\
\hline 24 & 15,863 & Hexacosano & 1,56 & 2601 & 2600 \\
\hline 25 & 16,689 & Heptacosano & 1,80 & 2695 & 2700 \\
\hline 26 & 17,617 & Octacosano & 1,46 & 2800 & 2800 \\
\hline 27 & 18,033 & $\mathrm{NI}$ & 1,37 & 2836 & \\
\hline 28 & 18,690 & Nanocosano & 2,12 & 2892 & 2900 \\
\hline TOTAL & & & 82,58 & & \\
\hline
\end{tabular}

* = índice de retenção calculado usando a equação de Van den Dool e Kratz.

** = Índice de retenção da literatura ${ }^{18}$ baseada na equação de Van den Dool e Kratz.

$\mathrm{NI}=\mathrm{Não}$ identificado

Os compostos encontrados em maiores porcentagens no óleo essencial dos frutos (OEPS 1) de K. coriacea foram: D-germacreno $(18,94 \%)$, neo-intermedeol (12,18\%), biciclogermacreno $(12,00 \%)$, viridiflorol $(9,30$ $\%)$, globulol $(8,76 \%)$, epi- $\alpha$-muurolol $(8,13 \%)$ e $\delta$-cadineno $(5,00 \%)$ (Figura 2$)$. Observa-se que o óleo essencial das folhas (OEPS 2 ) de $K$. coriacea é constituído principalmente de sesquiterpenos oxigenados e alcanos de cadeia longa, sendo os principais componentes: geranil linalool $(27,78 \%), 2-$ Acetato de $(2 E)$ tridecenol $(9,06 \%)$, $E$ Nerolidol (7,70\%) e $\alpha$-bisabolol (5,09 \%) (Figura 3). 
<smiles>C=C(C)CC/C=C(\C)CCC(/C=C/C(=C)CC)C(C)C</smiles>

(1)

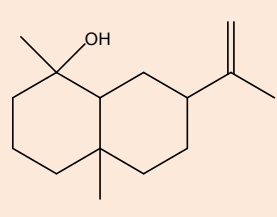

(2)

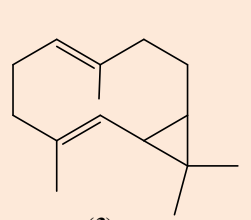

(3)

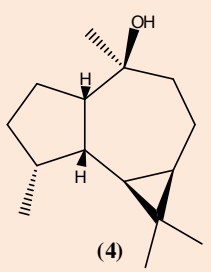

(4)

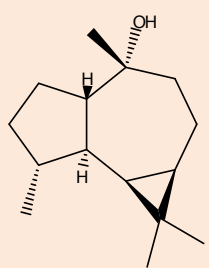

(5)

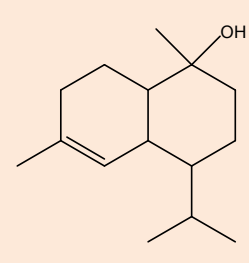

(6)

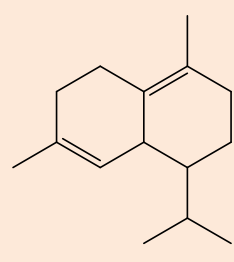

(7)

Figura 2. Estruturas químicas dos constituintes majoritários identificados no óleo essencial dos frutos frescos (OEPS 1) de $K$. coriacea D-germacreno (1), neo-intermedeol (2), biciclogermacreno (3), viridiflorol (4), globulol (5), epi- $\alpha$-muurolol (6) e $\delta$-cadineno (7)

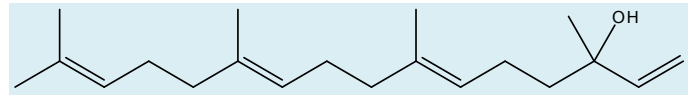

(1)

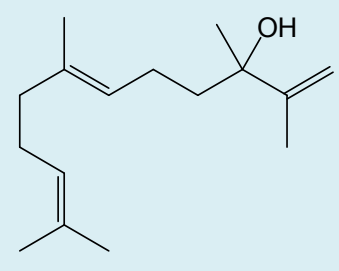

(3)

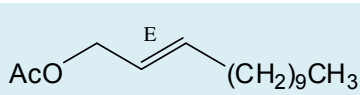

(2)

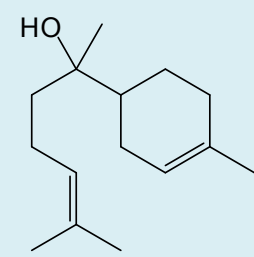

(4)

Figura 3. Estruturas químicas dos constituintes majoritários identificados no óleo essencial das folhas frescas (OEPS 2) de $K$. coriacea geranil linalool (1), 2- Acetato de (2E) tridecenol (2), E-

Nerolidol (3) e $\alpha$-bisabolol (4)

Em estudos anteriores, o óleo essencial das folhas de $K$. coriacea apresentou aproximadamente $85 \%$ de constituintes voláteis, em que foram identificados os sesquiterpenos: D-germacreno $(24,2 \%)$, o trans-carofileno (15,5\%), biciclogermaceno $(11,6 \%)$, e cerca de $5 \%$ do óleo essencial eram correspondente aos três isomeros do bisabolol ( $\beta$-bisabolol, epi- $\alpha$ - bisabolol e $\alpha$ bisabolol). ${ }^{2}$ Neste mesmo trabalho, os autores avaliaram também a composição química do óleo essencial da casca e da madeira de $K$. coriacea e identificaram os alcanos como os componentes majoritários, sendo os principais: hexacosano, heptacosano, octacosano, e nonacosano. Ressalta-se ainda que estes mesmos alcanos foram encontrados em nosso estudo químico do óleo essencial das folhas de $K$. coriacea coletada no estado de Goiás. Outro relato na literatura sobre o estudo químico com o óleo essencial das folhas da espécie Kielmeyera rugosa Choisy, coletada no estado de Sergipe demonstrou que os principais componentes são: o $\alpha$-cubebeno, $\alpha$-copaeno, transcariofileno e $\delta$-cadineno, representando cerca de $10 \%$ do óleo essencial. ${ }^{20}$ Esses compostos também foram identificados em K. coriacea, porém em diferentes 
concentrações, totalizando $24,4 \%$ do óleo essencial estudado.

Essas diferenças são comuns, porque a composição química de óleos essenciais varia de acordo com vários fatores, como o horário e época de colheita, o ataque de patógenos influencia na produção e variabilidade dos óleos, além disso, a localização, temperatura, idade e parte da planta também atuam de maneira significativa. ${ }^{21-23}$

Os efeitos dos óleos essenciais dos frutos e folhas de $K$. coriacea na proliferação e viabilidade de células humanas tumorais MDA-MB-231 (tumor da mama) e DU-145 (tumor de próstata) e células não tumorais $\mathrm{FH}$ (fibroblastos humanos) podem ser observados na Figura 4.

Estes resultados demonstraram que 0 OEPS 1 inibe a proliferação celular da linhagem de tumor de mama (MDA-MB-231) em $38,5 \%$ e da linhagem de tumor da próstata (DU-145) em 40,7\% na maior concentração testada $(100 \mu \mathrm{g} / \mathrm{mL})$, bem como inibe a proliferação em todas as concentrações testadas em células não tumorais (FH). Entretanto, OEPS 2 não se mostrou promissor para a atividade antitumoral, uma vez que este não exibiu nenhuma atividade frente às células humanas tumorais testadas. Em adição, o OEPS 2 mostrou-se citotóxico, uma vez que foi ativo em todas as concentrações testadas para as células não tumorais (FH fibroblastos humanos).

O D-germacreno (12,95\%) presente no óleo essencial das folhas de Pinus eldarica foi considerado o responsável pela sua atividade citotóxica. $^{24}$ Já a atividade citotóxica observada para o óleo essencial de $P$. aequale foi atribuído principalmente pela associação sinérgica envolvendo os sesquiterpenos D-germacreno e o biciclogermacreno. ${ }^{25} \quad \mathrm{Em}$ geral os sesquiterpenos do tipo elemeno, são considerados inibidores de proliferação celular, estimulantes de apoptose e indutores de paragem do ciclo celular na célula maligna. Adicionalmente, há relatos na literatura que o $\beta$-elemeno apresentou atividade anticancerígena em células do cérebro, laringe, pulmão, mama, próstata, colo do útero, cólon e do ovário. ${ }^{26-29}$

Outros estudos demonstraram que óleo essencial das folhas de Annona vepretorum contendo como constituintes principais o biciclogermacreno $(35,71 \%)$, espatulenol $(18,89 \%)$ e $D$-germacreno $(3,27 \%)$ apresentou atividade antitumoral promissora, inibindo em $34,46 \%$ o crescimento tumoral in vitro. No mesmo trabalho, o espatulenol foi testado de forma isolada e apresentou os seguintes valores de $\mathrm{IC}_{50}$ para B16-F10melanoma de rato $\left(11.67 \mu \mathrm{g} \mathrm{mL}^{-1}\right)$, HepG2carcinoma hepatocelular humano $(11.19 \mu \mathrm{g}$ $\left.\mathrm{mL}^{-1}\right), \quad \mathrm{HL}-60$ - leucemia promielocítica humana $\left(3.79 \mu \mathrm{g} \mathrm{mL}^{-1}\right), \mathrm{K} 562$ - leucemia mielóide crônica humana e (11.38 $\left.\mu \mathrm{g} \mathrm{mL}^{-1}\right)$ PBMCs-células mononucleares do sangue periférico humano ativadas com concanavalina (15.59 $\mu \mathrm{g} \mathrm{mL}^{-1}$ ), sugerindo que o espatulenol contribuiu de forma significativa para o efeito antitumoral desse óleo essencial. ${ }^{30}$ No óleo essencial das folhas de Nectandra leucantha, também foram encontrados o biciclogermacreno (28,44\%), espatulenol $(5,82 \%)$, além do germacreno $(7,34 \%)$, globulol $(5,25 \%), \gamma$ - Cadineno $(0,26$ $\%)$ e $\circ \delta$-Cadineno (0,99 \%),e exibiram atividade citotóxica significativa contra B16F10-Nex2-melanoma marino $\left(\mathrm{IC}_{50} 33 \pm\right.$ $1 \mu \mathrm{g} \mathrm{mL}^{-1}$ ), U87- gliobastoma humano ( $\mathrm{IC}_{50}$ 75,95 $\pm 0,03 \mu \mathrm{g} \mathrm{mL}{ }^{-1}$ ) e HeLa-carcinoma cervical humano $\left(\mathrm{IC}_{50} 60 \pm 12 \mu \mathrm{g} \mathrm{mL} \mathrm{L}^{-1}\right)$. $\mathrm{O}$ principal composto identificado, Biciclogermacreno, exibiu $I C_{50}$ variando de 3,1 $\pm 0,2$ a $21 \pm 6 \mu \mathrm{gL}^{-1}$. 
A
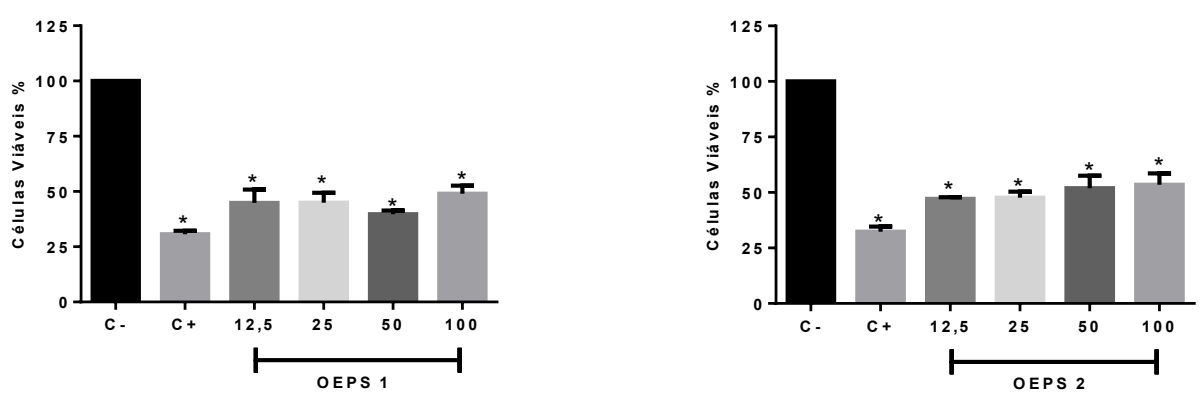

B
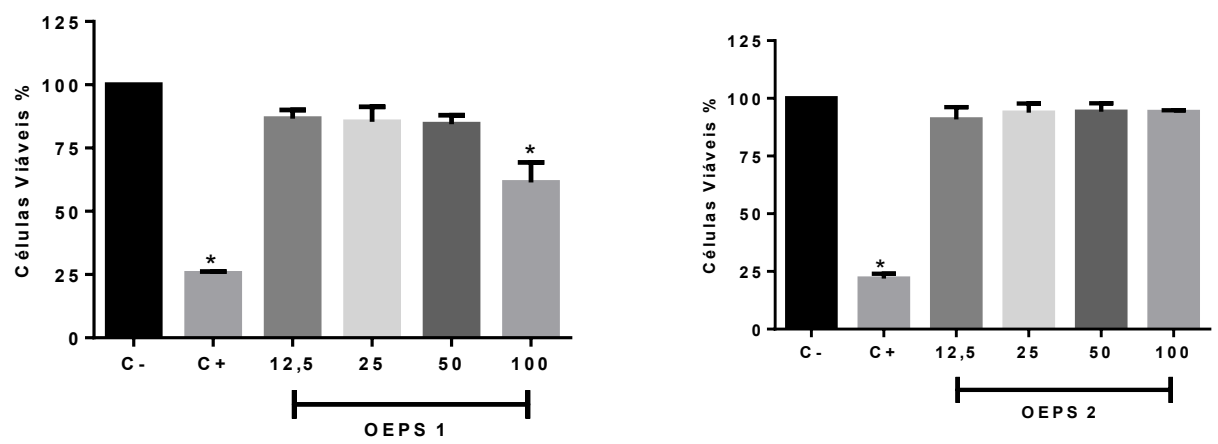

C
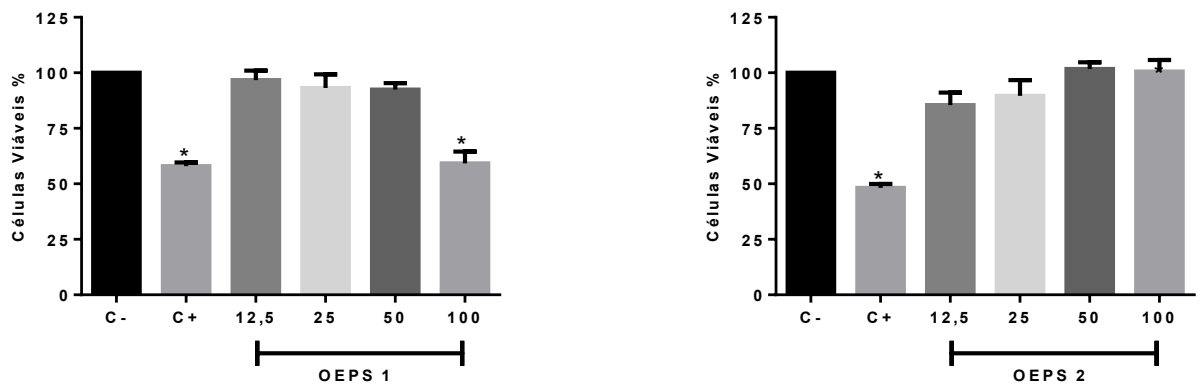

Figura 4. Efeitos de diferentes concentrações $(12,5 ; 25 ; 50$ e $100 \mu \mathrm{g} / \mathrm{mL}$ ) dos óleos essenciais dos frutos (OEPS 1 ) e das folhas (OEPS 2) de $K$. coriacea na proliferação celular nas células não tumorais $\mathrm{FH}$ (fibroblastos) (A), nas células tumorais MDA-MB-231 (tumor de mama) (B) e DU-145 (tumor de próstata) (C). O controle negativo (C-) corresponde às células tratadas apenas meio de cultura suplementado com SFB e o controle positivo $(\mathrm{C}+)$ corresponde às células tratadas com o quimioterápico, doxorrubicina. Os resultados foram comparados através da análise de variância one-way (ANOVA) seguido pelo teste de comparação múltipla de Dunnet $\left({ }^{*} p<0,01\right)$ 


\section{Conclusão}

O óleo essencial dos frutos (OEPS 1 ) de $K$. coriacea exibiu uma mistura complexa de sesquiterpenos hidrocarbonados $(45,9 \%)$ e sesquiterpenos oxigenados (54,1\%). Já o óleo essencial das folhas (OEPS 2) apresentou na sua maioria sesquiterpenos oxigenados $(87,7$ $\%)$. Este é o primeiro relato da composição química do óleo essencial dos frutos de Kielmeyera coriacea, contribuindo significativamente para $\mathrm{o}$ conhecimento desta espécie.

O óleo essencial dos frutos (OEPS 1 ) inibiu a proliferação celular das linhagens tumorais DU-145 (40,7\%) e MDA-MB-231 (38,5\%) e das celulas não tumorais $(\mathrm{FH})$, enquanto que o óleo essencial das folhas (OEPS 2) não exibiu atividade frente a nenhuma linhagem tumoral testada. Apesar da citotoxicidade apresentada pelo OEPS 1 , este deve passar por fracionamentos na tentativa de encontrar substância que apresentem maior seletividade para células cancerosas.

\section{Referências Bibliográficas}

${ }^{1}$ Pereira, B. A. S. P.; Venturoli, F.; Carvalho, F.A. Florestas estacionais no Cerrado: uma visão geral. Pesquisa Agropecuária Tropical 2011, 41, 446. [Link]

${ }^{2}$ Martins, C. M.; Nascimento, E. A.; Morais, S. A. L.; Oliveira, A.; Chang, R.; Cunha, L. C. S.; Martins, M. M.; Martins, C. H. G.; Moraes, T. S.; Rodrigues, P. V.; Silva, C. V.; Aquino, F. J. T. Chemical Constituents and Evaluation of Antimicrobial and Cytotoxic Activities of Kielmeyera coriacea Mart. \& Zucc. Essential Oils. Evidence-Based Complementary and Alternative Medicine 2015, 1. [CrossRef]

${ }^{3}$ Ruhfel, B. R.; Bittrich, V.; Bove, C. P.; Gustafsson, M. H.; Philbrick, C. T.; Rutishauser, R.; Xi, Z.; Davis, C. C. Phylogeny of the clusioid clade (Malpighiales): evidence from the plastid and mitochondrial genomes. American Journal of Botany 2011, 98, 306. [CrossRef] [PubMed]
${ }^{4}$ Caddah, M. K.; Mayer, J. L. S.; Bittrich, V.; Amaral, M. C. E. Species limits in the Kielmeyera coriacea complex (Calophyllaceae)-a multidisciplinary approach. Botanical Journal of the Linnean Society 2012, 168, 101. [CrossRef]

${ }^{5}$ Pinheiro, L.; Nakamura, C. V.; Filho, B. P. D.; Ferreira, A. G.; Young, M. C. M.; Cortez, D. A. G. Antibacterial xanthones from Kielmeyera variabilis mart. (Clusiaceae). Memórias do Instituto Oswaldo Cruz 2003, 98, 549. [CrossRef]

${ }^{6}$ Lorenzi, H.; Árvores brasileiras: manual de identificação e cultivo de plantas arbóreas nativas do Brasil, Editora Plantarum-col. illus.: Nova Odessa, 352, p. 1992.

${ }^{7}$ Gomides, N. A. M. T.; Caixeta Neta, A.; Severino, R. P.; Severino, V. G. P.; Guarim Neto, G.; Etnobotânica de Kielmeyera coriacea Mart e Zucc. In: Estudos Interdisciplinares em Ciências Biológicas, Saúde, Engenharias e Gestão, 1a. ed., Blucher: São Paulo, 2016, v. 1, p.177-197

${ }^{8}$ Figueiredo, C. R.; Matsuo, A. L.; Massaoka, M. H.; Girola, N.; Azevedo, R. A.; Rabaça, A. N.; Farias, C. F.; Pereira, F. V.; Matias, N. S.; Silva, L. P.; Rodrigues, E. G.; Lago, J. H. G.; Travassos, L. R.; Silva, R. M. G. Antitumor Activity of Kielmeyera Coriacea Leaf Constituents in Experimental Melanoma, Tested in Vitro and in Vivo in Syngeneic Mice. Advanced Pharmaceutical Bulletin 2014, 4, 429. [CrossRef] [PubMed]

${ }^{9}$ Vasconcellos, M. C. B. L. M.; Tese Doutorado, Universidade Estadual de Campinas, 2008. [Link]

${ }^{10}$ Silva, R. M. G.; Rodrigues, D. T. M.; Augustos, F. S.; Valadares, F.; Neto, P. O.; Santos, L.; Silva, L. P. Antitumor and cytotoxic activity of Kielmeyera coriacea mart. Zucc. and Pyrostegia venusta (ker-gawl.) Miers extracts. Journal of Medicinal Plants Research 2012, 6, 4142. [CrossRef]

${ }^{11}$ Mesquita, M. L.; Paula, J. E.; Pessoa, C.; Moraes, M. O.; Lotufo, L. V.; Grougnet, R.; Michel, S.; Tillequin, F.; Espindola, L. S. Cytotoxic activity of Brazilian Cerrado plants used in traditional medicine against cancer 
cell lines. Journal of Ethnopharmacology 2009, 123, 439. [CrossRef] [PubMed]

12 Mesquita, M. L.; Araújo, R. M.; Bezerra, D. P.; Filho, R. B.; Paula, J. E.; Silveira, E. R.; Pessoa, C.; Moraes, M. O.; Costa-Lotufo, L. V.; Espindola, L. S. Cytotoxicity of $\delta$-tocotrienols from Kielmeyera coriacea against cancer cell lines. Bioorganic \& Medicinal Chemistry 2011, 19, 623. [CrossRef] [PubMed]

13 Sousa, V. R.; Tese de Doutorado, Universidade Federal da Bahia, 2005.

14 Roux, D.; Hadi, H. A.; Thoret, S.; Guénard, D.; Thoison, O.; Pais, M.; Sévenet, T. Structure-activity relationship of polyisoprenyl benzophenones from Garcinia pyrifera on the tubulin/microtubule system. Journal of Natural Products 2000, 63, 1070. [CrossRef] [PubMed]

${ }^{15}$ Raut, J. S.; Karuppayil, S. M. A status review on the medicinal properties of essential oils. Industrial Crops and Products 2014, 62, 250. [CrossRef]

${ }^{16}$ Adorjan, B.; Buchbauer, G. Biological properties of essential oils: an updated review. Flavour and Fragrance Journal 2010, 25, 407. [CrossRef]

${ }^{17}$ Siqueira, C. A. T.; Oliani, J.; Sartoratto, A.; Queiroga, C. L.; Moreno, P. R. H.; Reimão, J. Q.; Tempone, A. G.; Fischer, D. C. H. Chemical constituents of the volatil oil from leaves of Annona coriacea and in vitro antiprotozoal activity. Revista Brasileira de Farmacognosia 2011, 21, 33. [CrossRef]

${ }^{18}$ Adams, R. P.; Identification of essential oil componentes by gas chromatography quadrupole mass spectroscopy, Card Stream I L: Allured, 2001.

${ }^{19}$ Mosmann, T. Rapid colorimetric assay for cellular growth and survival: application to proliferation and cytotoxicity assays. Journal of Immunological Methods 1983, 65, 55. [CrossRef] [PubMed]

${ }^{20}$ Andrade, M. S.; Sampaio, T. S.; Nogueira, P. C. L.; Ribeiro, A. S.; Bittrich, V.; Amaral, M. C. Volatile compounds of the leaves, flowers and fruits of kielmeyera rugosa Choisy
(Clusiaceae). Flavour and Frangrance Jounal 2007, 22, 49. [CrossRef]

${ }^{21}$ Xavier, M. N.; Alves, J. M.; Carneiro, N. S.; Souchie, E. L.; Silva, E. A. J.; Martins, C. H. G.; Ambrosio, M. A. L. V.; Egea, M. B.; Alves, C. C. F.; Miranda, M. L. D. Composição química do óleo essencial de Cardiopetalum calophyllum Schltdl. (Annonaceae) e suas atividades antioxidante, antibacteriana e antifúngica. Revista Virtual de Química 2016, 8, 1433. [CrossRef]

22 Paulus, D.; Valmorbida, R.; Toffoli, E.; Nava, Ga. Teor e composição química de óleo essencial de cidró em função da sazonalidade e horário de colheita. Horticultura Brasileira 2013, 31, 203. [CrossRef]

23 Rocha, R. P.; Melo, E. C.; Barbosa;L. C. A.; Santos, R. H. S.; Cecon, P. R.; Dallacort, R.; Santi, A. Influence of plant age on the content and composition of essential oil of Cymbopogon citratus (DC.) Stapf. Journal of Medicinal Plants Research 2014, 8, 1121. [CrossRef]

${ }^{24}$ Sarvmeili, N.; Jafarian-Dehkordi, A.; Zolfaghari, B. Cytotoxic effects of Pinus eldarica essential oil and extracts on HeLa and MCF-7 cell lines. Research in Pharmaceutical Sciences 2016, 11, 476. [CrossRef] [PubMed]

25 Silva, J. K.; Pinto, L. C.; Burbano, R. M.; Montenegro, R. C.; Andrade, E. H.; Maia, J. G. Composition and cytotoxic and antioxidant activities of the oil of Piper aequale Vahl. Lipids in Health and Disease 2016, 15, 174. [CrossRef] [PubMed]

${ }^{26}$ Wang, G.; Li, X.; Huang, F.; Zhao, J.; Ding, H. Antitumor effect of beta-elemene in nonsmall-cell lung cancer cells is mediated via induction of cell cycle arrest and apoptotic cell death. Cellular and Molecular Life Sciences 2005, 62, 881. [CrossRef] [PubMed]

27 Li, X.; Wang. G.; Zhao, J.; Ding, H.; Cunningham, C.; Chen, F.; Flynn, D. C.; Reed, E.; Li, Q. Q. Antiproliferative effect of betaelemene in chemoresistant ovariancarcinoma cells is mediated through arrest of the cell cycle at the G2-M phase. Cellular and 
Molecular Life Science, 2005, 62, 894. [CrossRef] [PubMed]

${ }^{28}$ Yao, Y. Q.; Ding, X.; Jia, Y. C.; Huang, C. X.; Wang, Y. Z.; Xu, Y. H. Anti-tumor effect of beta-elemene in glioblastoma cells depends on p38 MAPK activation. Cancer Letters 2008, 264, 127. [CrossRef] [PubMed]

29 Liu, J.; Zhang, Y.; Qu, J.; Xu, L.; Hou, K.; Zhang, J.; Qu, X.; Liu, Y.; [beta]-Elemeneinduced autophagy human gastric cancer cells from undergoing apoptosis. BMC Cancer 2011, 11, 183. [CrossRef] [PubMed]

${ }^{30}$ Bomfim, L. M.; Menezes, L. R. A.; Rodrigues, A. C. B. C.; Dias, R. B.; Rocha, C. A.
G.; Soares, M. B. P. Neto, A. F. S.; Nascimento, M. P.; Campos, A. F. . Silva, L. C. R. C.; Costa, E. V.; Bezerra, D. P. Antitumor Activity of the Microencapsulation of Annona vepretorum Essential Oil. Basic \& Clinical Pharmacology \& Toxicology 2016, 118, 208. [CrossRef] [PubMed]

${ }^{31}$ Grecco, S. S.; Martins, E. G. A.; Girola, N.; Figueiredo, C. R.; Matsuo, A. L.; Soares, M. G.; Bertoldo, B. C.; Sartorelli, P.; Lago, J. H. G. Chemical composition and in vitro cytotoxic effects of the essential oil from Nectandra leucantha leaves. Pharmaceutical Biology 2015, 53,133. [CrossRef] [PubMed] 